Research Article

\title{
Differential Feeding Preference and Performance of Leafworm Spo- doptera litura Fabricius (Lepidoptera: Noctuidae) on some Cultivars of Potato (Solanum tuberosum L.)
}

\author{
Muhammad Shakil Ahmad ${ }^{1, *}$, Muhammad Afzal ${ }^{1}$, Sylvain Nafiba Ouedraogo ${ }^{2}$ and Muhammad Zeeshan \\ Majeed $^{1}$
}

${ }^{1}$ Department of Entomology, College of Agriculture, University of Sargodha, Sargodha 40100, Pakistan; ${ }^{2}$ Institut des Sciences del'Environnement et du Développement Rural (ISEDR), Université de Dédougou, BP 176, Dédougou, Burkina Faso.

\begin{abstract}
Leafworm Spodoptera litura Fabricius is a highly polyphagous pest of food, forage, vegetable and horticultural crops. This sporadic species is becoming an emerging threat to the potato crop in central Punjab and is being evidenced infesting potato crop in Sargodha, Faisalabad and Okara districts. This in-vitro study assessed the comparative feeding preference, food consumption and utilization rates and larval development of $S$. litura on different white and red skinned potato cultivars. Feeding bioassays revealed that all parameters including leaf weight loss, larval weight gain, relative food consumption and growth rates and conversion efficiency of the ingested food were statistically significant $(P \leq 0.05)$. Exotic potato cultivars Diamant, Desiree and Asterix exhibited maximum leaf consumption and larval weight gain (i.e. 264.61, 259.37 and $233.01 \mathrm{mg}$ and $121.46,120.17,120.13 \mathrm{mg}$, respectively) concomitantly with maximum values of relative growth rate (RGR), relative consumption rate (RCR) and ingested food conversion efficiency (ECI). Cultivars Lady Rosetta, Cardinal, Ajax, Kuroda and Sante exhibited intermediate values. Minimum feeding preference and susceptibility to $S$. litura was shown by the native potato cultivars Faisalabad Red and Faisalabad White with minimum food consumption, larval weight gain, RGR, RCR and ECI values, and hence are recommended to indigenous potato growers for commercial cultivation in areas where $S$. litura threatens potato crop.

Received | January 09, 2021; Accepted | March 21, 2021; Published | June 24, 2021

*Correspondence | Muhammad Shakil Ahmad, Department of Entomology, College of Agriculture, University of Sargodha, Sargodha 40100, Pakistan; Email: shakilahmadsheraz@gmail.com

Citation | Ahmad, M.S., M. Afzal, S.N. Ouedraogo and M.Z. Majeed. 2021. Differential feeding preference and performance of leafworm Spodoptera litura Fabricius (Lepidoptera: Noctuidae) on some cultivars of potato (Solanum tuberosum L.). Sarhad Journal of Agriculture, 37(3): 791-796.

DOI | https://dx.doi.org/10.17582/journal.sja/2021/37.3.791.796

Keywords | Feeding preference, Potato cultivars, Larval growth parameters, Relative food consumption, Spodoptera litura
\end{abstract}

\section{Introduction}

$\mathrm{P}$ otato (Solanum tuberosum L.) is one of the major staple food crops in the world and is rich in nutrients, particularly in potassium, vitamin $\mathrm{C}$ and dietary fiber. It is regarded as fourth most imperative food crop, after maize, wheat and rice cultivation in Pakistan (Majeed and Muhammad, 2018). It is cultivated on an area of about 0.18 million hectares with an annual production of 3.8 million tons sharing about 27 and $40 \%$ of the area and production of vegetables in the country (Khan et al., 2020). Punjab province is the leading potato producing area followed by Khyber Pakhtunkhwa, Baluchistan and Sindh (GOP, 2017). In Punjab province, districts Okara, Sahiwal, Pakpatan, Chiniot and Khanewal are the major potato growing areas.

Although Pakistan is self-sufficient in potato production, the country is far behind than other potato 
producing countries regarding the potato production per unit area. Potato crop is affected by several factors including insect pests and diseases (Weber, 2012; Majeed and Muhammad, 2018; Kroschel et al., 2020). Among the insect pests attacking the potato crop, leafworm Spodoptera litura is regarded as a sporadic serious pest of this crop. Considerable qualitative and quantitative losses are incurred to potato crop by $S$. litura infestations (Bhushan et al., 2010; Kroschel et al., 2020). It is a highly polyphagous pest with a wide range of host plants including maize, cotton, rice, potato, okra, tomato, cabbage, cauliflower, berseem and cucurbits (Ahmad et al., 2013; Ullah et al., 2016; Bragard et al., 2019). Larvae of S. litura feed gregariously and skeletonize the potato foliage and severe infestation can cause complete defoliation of the crop. Under agro-climatic conditions of Indo-Pak regions, $S$. litura has been a detrimental pest of potato crop (Basavaraju et al., 2010; Ahmad et al., 2013; Bade and Chandele, 2014; Kroschel et al., 2020).

S. litura is being regarded as a potentially serious threat to potato production in Pakistan. Its infestation has been reported more frequently since last few years in all potato growing areas of the country. As screening host plant material against potential insect pests has been one of the basic and essential elements of integrated pest management (Gebremdein, 2018; Selvanarayanan et al., 2020), this study was carried out with an aim to determine the feeding preference and larval developmental performance of leafworm $S$. litura on different white and red skinned cultivars of potato which are commonly grown in different parts of the country. The objective was to have a comparative assessment of feeding potential and performance of the pest on different potato cultivars and to find out which potato cultivars relatively exhibit more resistance or tolerance to $S$. litura infestations.

\section{Materials and Methods}

This study was carried out in the laboratory of the Department of Entomology, College of Agriculture, University of Sargodha, Pakistan.

\section{Potato cultivars and rearing of S. litura}

Ten most commonly grown potato cultivars (varieties) including five white skinned cultivars (Ajax, Diamant, Faisalabad White, Lady Rosetta and Santé) and five red skinned cultivars (Asterix, Cardinal, Desiree, Faisalabad and Red Kuroda) were procured from the indigenous progressive potato growers and from the Potato Research Institute, Sahiwal, Pakistan. These cultivars were sown in the farm area of the College of Agriculture, University of Sargodha, following all standard agronomic practices recommended by the Potato Research Institute.

Late instar larvae of $S$. litura were collected from the potato fields located in Chiniot, district Faisalabad (31 43'29' N and 73 03'35"E; Punjab, Pakistan). These field collected larvae were brought to the laboratory of Entomology and were reared on an artificial (chickpea flour-based) diet (Gupta et al., 2005). Test population of $S$. litura larvae was ensured to be homogenous by rearing them to $F_{4}$ generations. Only healthy and active freshly molted $3^{\text {rd }}$ instar larvae were used in all feeding bioassays.

\section{Experimental layout}

Feeding potential and developmental performance of $S$. litura $3^{\text {rd }}$ instar larvae were determined according to the slightly modified protocol of Greenberg et al. (2001) and Ullah et al. (2016). Young and fresh leaves of above mentioned ten potato cultivars were collected from the field and were washed with clean tap water and allowed to be drained for few a minutes before these were put in sterilized $90 \mathrm{~mm}$ glass Petri plates. A layer of $1.5 \%$ agar was maintained at the bottom of Petri plates to ensure that leaves remained fresh for $24 \mathrm{~h}$. One freshly molted healthy and active $3^{\text {rd }}$ instar larva of $S$. litura was released in each Petri plate with the help of a soft camel hair brush and Petri-plates were incubated in an environmental chamber at controlled conditions i.e. at $25 \pm 2{ }^{\circ} \mathrm{C}$ temperature, $60 \pm 5 \%$ relative humidity and at $16 \mathrm{~h} \mathrm{L:} 8 \mathrm{~h}$ D photoperiod. Data regarding leaf consumption and larval growth were recorded at each $24 \mathrm{~h}$ interval. Experimental design was completely randomized with ten replications maintained for each treatment.

Determination of leaf weight loss and larval weight gain Initially weighed $3^{\text {rd }}$ instar larvae were released on a weighed leaf in a Petri plate to record the feeding. Ten independent replicates were maintained for each potato cultivar. Control treatment included a Petri plate with a potato leaf but without any $S$. litura larva. The leaves and larvae were weighed after $24 \mathrm{~h}$ and were replaced by the new weighed leaves. This process continued after every $24 \mathrm{~h}$ for four consecutive days. Daily leaf weight loss or food consumption and larval weight gain were calculated by working out the 
difference of weights and were further corrected by the weight of leaves obtained in the control treatments.

\section{Determination of larval growth and developmental} parameters

Pre-ingestive parameters i.e. relative leaf consumption by $S$. litura larvae (RCR) and the relative growth rate of $S$. litura larvae (RGR), and the post-ingestive food utilization parameter i.e. the efficiency of conversion of ingested food (ECI), were calculated according to the following formula (Ullah et al., 2016).

$$
\begin{gathered}
\text { Relative consumption rate (RCR) }=\left(\frac{I}{B}\right) \times T \\
\text { Relative growth rate (RGR) }=\left(\frac{\Delta \mathrm{B}}{B I}\right) \times T \\
\text { Conversion efficiency of ingested food }(\mathrm{ECI})=\left(\frac{B}{I}\right) \times 100
\end{gathered}
$$

Where; I is the weight of food (leaf) consumed (mg), $B$ is the larval weight gain $(\mathrm{mg})$ and $T$ is the feeding duration (day), $\Delta B$ is the body weight change of larva $(\mathrm{mg})$ and $B I$ is the initial weight of larva.

\section{Data analysis}

Apart from the graphical representation, data were subjected to statistical analysis using Statistix V. 8.1 (Analytical Software, Tallahassee, Florida) software. Treatments were compared by running one-way analysis of variance (ANOVA) followed by Tukey's honestly significant difference (HSD) test at standard level of significance i.e. at $p=0.05$.

\section{Results and Discussion}

A differential trend was observed regarding the feeding and performance parameters of $3^{\text {rd }}$ instar larvae of $S$. litura on different red and white skinned cultivars of potato. All parameters including leaf weight loss, larval weight, relative growth and food consumption rates and conversion efficiency of ingested food were statistically significant at $p \leq$ 0.05 (Table 1). Maximum leaf consumption was recorded in potato cultivar Diamant $(264.61 \pm 12.91$ $\mathrm{mg})$ followed by Lady Rosetta $(259.37 \pm 14.39 \mathrm{mg})$ and Asterix (233.01 $\pm 14.57 \mathrm{mg})$, while minimum food consumption was found for the cultivar Ajax (161.79 $\pm 17.06 \mathrm{mg})$, Faisalabad Red $(194.47 \pm 19.24$ $\mathrm{mg})$ and Faisalabad White $(168.79 \pm 16.44 \mathrm{mg}$ ) (Figure 1). Similarly, $3^{\text {rd }}$ instar larvae of S. litura preferred and gained maximum weight while feeding on the leaves of potato cultivar Diamant (121.46 $\pm 11.92 \mathrm{mg}$ ) followed by Desiree $(120.17 \pm 10.54 \mathrm{mg})$ and Asterix $(120.13 \pm 10.47 \mathrm{mg})$, while minimum larval weight gain was noted for cultivar Faisalabad Red (89.41 \pm $10.02 \mathrm{mg})$, Faisalabad White $(78.13 \pm 10.04 \mathrm{mg})$ and Ajax $(89.69 \pm 10.85 \mathrm{mg})$ (Figure 1).

Table 1: Analysis of variance (ANOVA) regarding the feeding and development characteristics of $3^{\text {rd }}$ instar larvae of Spodoptera litura on different potato cultivars.

$\begin{array}{lllll}\text { Parameters } & \text { DF SS } & \text { MS } & \text { F-value } \\ \text { Leaf weight loss }(\mathrm{mg}) & 9 & 29144.1 & 3238.23 & 389^{*} \\ \text { Larval weight gain }(\mathrm{mg}) & 9 & 6607.38 & 734.154 & 190^{* *} \\ \text { RCR }(\mathrm{mg} / \mathrm{mg} / \mathrm{d}) & 9 & 0.36693 & 0.0407 & 27.5^{* *} \\ \text { RGR }(\mathrm{mg} / \mathrm{mg} / \mathrm{d}) & 9 & 0.05866 & 0.0065 & 61.3^{* * *} \\ \text { ECI }(\%) & 9 & 182.449 & 20.272 & 26.8^{* *}\end{array}$

$F$-values with symbols ****, *** and *are significant at $p \leq 0.001,0.01$ and 0.05 , respectively (one-way factorial ANOVA; HSD).
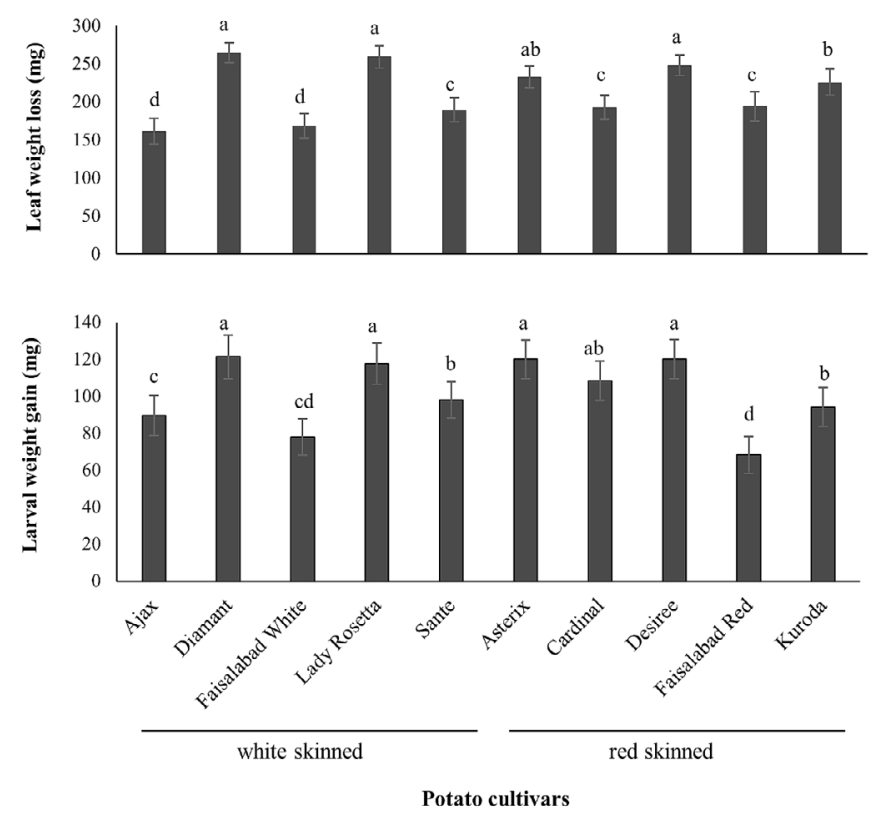

Figure 1: Leaf consumption and weight gain values (mean $\pm S E$ ) of $3^{\text {rd }}$ instar larvae of Spodoptera litura feeding on different potato cultivars. Alphabets at bar tops indicate significant difference among the treatments (one-way ANOVA; HSD at $\alpha=0.05$ ).

Regarding the relative growth rate (RGR), $3^{\text {rd }}$ instar larvae of $S$. litura showed maximum growth when offered leaves of potato cultivars Diamant $(0.52 \pm 0.04$ $\mathrm{mg} / \mathrm{mg} /$ day $)$ and Desiree $(0.52 \pm 0.06 \mathrm{mg} / \mathrm{mg} /$ day $)$, followed by the cultivars Lady Rosetta $(0.50 \pm 0.06$ $\mathrm{mg} / \mathrm{mg} /$ day $)$ and Asterix $(0.47 \pm 0.06 \mathrm{mg} / \mathrm{mg} /$ day $)$. However, there was no statistical difference among Diamant and Desiree $(P \leq 0.05)$. Minimum relative growth rate was recorded for the cultivars Faisalabad $\operatorname{Red}(0.30 \pm 0.04 \mathrm{mg} / \mathrm{mg} /$ day $)$ and Faisalabad White $(0.26 \pm 0.04 \mathrm{mg} / \mathrm{mg} /$ day) (Figure $2 \mathrm{~A})$. In case of relative consumption rate (RCR), the highest 
consumption rate was recorded for the cultivars Diamant and Desiree (i.e. $2.55 \pm 0.17$ and $2.41 \pm$ $0.17 \mathrm{mg} / \mathrm{mg} /$ day, respectively), followed by cultivars Asterix $(2.31 \pm 0.15 \mathrm{mg} / \mathrm{mg} /$ day $)$ and Lady Rosetta (2.17 $\pm 0.17 \mathrm{mg} / \mathrm{mg} /$ day). Cultivars Faisalabad Red and Faisalabad White exhibited minimum relative food consumption rates (i.e. $1.51 \pm 0.10$ and $1.72 \pm$ $0.14 \mathrm{mg} / \mathrm{mg} /$ day, respectively), while potato cultivars Cardinal, Ajax and Kuroda showed intermediate consumption rates (Figure 2B). A similar trend of significance was observed regarding the efficiency of conversion of ingested food (ECI) which was significantly high in cultivars Diamant (67.10 \pm 9.42\%) and Desiree (64.98 $\pm 10.20 \%)$, followed by cultivar Asterix $(59.86 \pm 3.94 \%)$. Cultivars Cardinal, Ajax, Kuroda, Lady Rosetta and Sante exhibited intermediate ECI values, while minimum ECI values were recorded for cultivars Faisalabad Red and Faisalabad white (Figure 2C). Nevertheless, there was no statistical difference among white and red skinned potato cultivars for all of the measured larval feeding and performance parameters. Moreover, average food (potato foliage) consumption and larval growth (weight gain) were found positively and significantly correlated (Pearson correlation coefficients $(\mathrm{r})=$ 0.934; $P \leq 0.001)$.

Growth and development of phytophagous insects depend on certain parameters such as how efficiently the ingested food material is being transformed into insect's biomass (Waldbauer, 1968; Nathan et al., 2005). Relative growth rate (RGR), relative consumption rate (RCR) and conversion efficiency of ingested food (ECI) are of prime importance regarding the assessment of host plants suitability and feeding potential and performance of insect pests (Reese, 1978).

As leafworm S. litura along with fall armyworm Spodoptera frugiperda is emerging as a potential pest of potato in all potato growing areas of Punjab, Pakistan. This study was aimed to screen out all commercially grown potato cultivars against the damage potential of $S$. litura. We assessed the relative feeding potential and development parameters (food consumption, larval weight gain, RGR, RCR and ECI) of $S$. litura larvae on ten different commercially grown potato cultivars.

Results revealed a significant difference for all studied parameters when $3^{\text {rd }}$ instar larvae of $S$. litura were fed on the leaves of different potato cultivars. Potato cultivars Faisalabad Red and Faisalabad White appeared to be least attractive and susceptible to S. litura infestation (Abbas et al., 2014). Less pest susceptibility of these potato cultivars are probably due to their native origin because these cultivars are selected under agro-climatic conditions of Pakistan under the umbrella of Ayub Agricultural Research Institute, Faisalabad (Hassan et al., 2015).
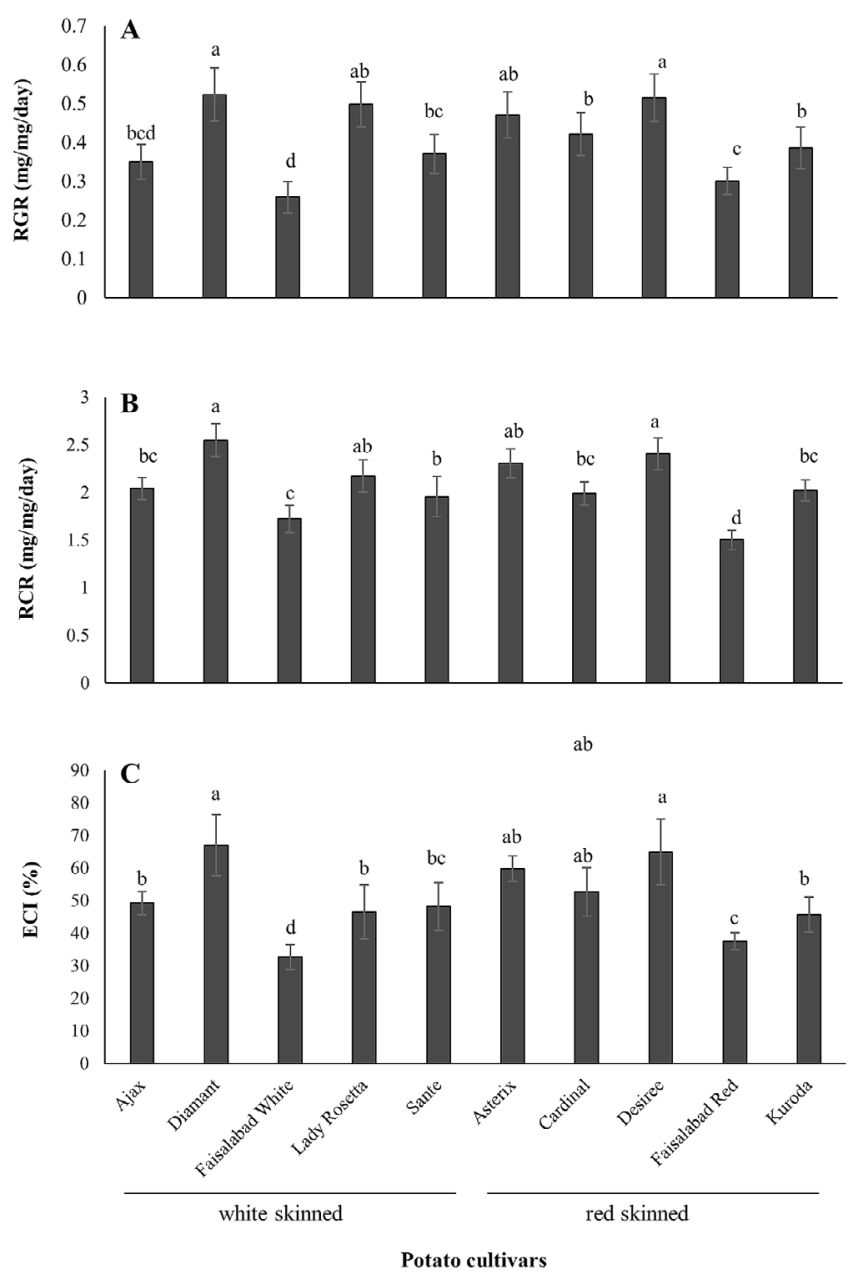

Figure 2: Food consumption and larval performance values (mean $\pm S E$ ) of $3^{\text {rd }}$ instar larvae of Spodoptera litura feeding on different potato cultivars. (A): relative growth rate $(R G R),(B)$ : relative consumption rate $(R C R)$ and $(C)$ : efficiency of conversion of ingested food (ECI). Alphabets at bar tops indicate significant difference among the treatments (one-way ANOVA; HSD at $\alpha=0.05$ ).

On the contrary, maximum food consumption and larval weight gain was observed for the potato cultivars Diamant, Desire and Lad Rosetta concomitantly exhibiting highest values of RGR, RCR and ECI as well. This means that the foliage of these potato cultivars was most suitable for the conversion to growth and biomass development of S. litura larvae, suggesting the maximum susceptibility of these cultivars to $S$. litura out in the field. These three potato 
cultivars are developed in Holland and Germany (Gregoriou et al., 1997). Exotic origin of these three potato cultivars would be one of the reasons for this observed high susceptibility to $S$. litura under prevailing climatic conditions of Punjab, Pakistan (Abbasi et al., 2004; Howlader and Hoque, 2018). As S. litura is endemic to South Asian regions (EPPO, 2015), successful exploitation of exotic host plants by native insect pests may be associated with the fitness cost including reduced feeding potential on ancestral native host plants and differential plant chemistries of exotic and native plant genotypes (Atijegbe et al., 2020).

\section{Conclusions and Recommendations}

In conclusion, $S$. litura larvae exhibited a differential feeding preference and growth parameters on the foliage of different potato cultivars. Exotic potato cultivars particularly Diamant, Desiree, Lady Rosetta and Cardinal showed maximum susceptibility (feeding preference) and suitability (ECI and RGR) and exhibited highest larval feeding potential and growth parameters. On the contrary, potato cultivars of native origin, particularly Faisalabad Red and Faisalabad White, appeared to be most tolerant and less attractive to $S$. litura, and hence are recommended to indigenous potato growers for the commercial cultivation in areas where $S$. litura threatens potato crop. Characterization of biochemical composition of preferred and non-preferred potato cultivars would provide more insight and better understanding of this differential feeding preference by $S$. litura as reported previously for other lepidopterous pests (Agosta, 2006; Atijegbe et al., 2020).

\section{Novelty Statement}

This in-vitro study encompasses the first comparative assessment of the feeding preference, food consumption potential and growth performance of Spodoptera litura larvae on different commercially grown potato cultivars and has demonstrated that exotic cultivars exhibit more susceptibility to $S$. litura infestations as compared to indigenously developed potato cultivars.

\section{Author's Contribution}

MSA and MZM: Conceived the idea and planned the experiment.
MSA: Carried out bioassays.

MSA and MZM: Wrote the first draft of the manuscript.

SNO: Did the statistical analyses of data and technically revised the manuscript.

MA: Provided the technical assistance and proofread the manuscript.

All authors read and approved the final manuscript.

\section{Conflict of interest}

The authors have declared no conflict of interest.

\section{References}

Abbas, W., M.N. Subhani, M. Ayub, M.M. Javed, S. Akhtar, M. Nasir and M. Attiq. 2014. Evaluation of potato lines/varieties for the resistant source against PVX, PVY and PLRV under natural field conditions. Int. J. Innovat. Sci. Math., 2: 24-37.

Abbasi, N.A., I.A. Hafiz and B. Fazal. 2004. Evaluation of exotic potato varieties in ecological conditions of Islamabad during autumn season. Int. J. Agric. Biol., 3: 479-482.

Agosta, S.J., 2006. On ecological fitting, plant-insect associations, herbivore host shifts, and host plant selection. Oikos, 114(3): 556-565. https:// doi.org/10.1111/j.2006.0030-1299.15025.x

Ahmad, M., A. Ghaffar and M. Rafiq. 2013. Host plants of leaf worm, Spodoptera litura (Fabricius) (Lepidoptera: Noctuidae) in Pakistan. Asian J. Agric. Biol., 1: 23-28.

Atijegbe, S.R., S. Mansfield, C.M. Ferguson, S.P. Worner and M. Rostás. 2020. Host range expansion of an endemic insect herbivore is associated with high nitrogen and low fibre content in exotic pasture plants. J. Chem. Ecol., 46: 544-556. https://doi.org/10.1007/s10886-02001183-5

Bade, B.A. and A.G. Chandele. 2014. Evaluation of Nomuraea rileyi (Farlow) Samson geographical isolates against Spodoptera litura (Fabricius) infesting potato. J. Agric. Sci. Technol., 39: 432437.

Basavaraju, B.S., P.R. Shashank, B. Doddabasappa, L. Vijayakumar and A.K. Chakravarthy. 2010. Efficacy of poison baits and biopesticides against Spodoptera litura Fab. (Lepidoptera: Noctuidae) in potato. Pest Manage. Hortic. Ecosyst., 16: 64-68.

Bhushan, V.S., V.R. Babu, K.D. Reddy and T. 
Umamaheswari. 2010. Efficacy of certain insecticides against Spodoptera litura (Fab.) on potato. Karnataka J. Agric. Sci., 23: 195-196.

Bragard, C., K. Dehnen-Schmutz. F. di Serio. P. Gonthier,M.A.Jacques,J.A.J.Miret and A.MacLeod. 2019. Pest categorisation of Spodoptera litura. Efsa J., 17(7). https://doi.org/10.2903/j. efsa.2019.5765

European and Mediterranean Plant Protection Organization. 2015. PM 7/124 (1) Spodoptera littoralis, Spodoptera litura, Spodoptera frugiperda, Spodoptera eridania. EPPO Bull., 45: 410444. https://doi.org/10.1111/epp.12258

Gebremdein, M.B., 2018. Varietal screening for resistance against field and storage crop pests: An implication for Ethiopian crop variety development. J. Plant Breed. Crop Sci., 10: 203-209. https://doi.org/10.5897/JPBCS2018.0728

GOP, 2017. Economic survey of Pakistan, 2018-19. Economic Adviser's Wing, Finance Division, Government of Pakistan, www.finance.gov.pk.

Greenberg, S.M., T.W. Sappington, B.C. Legaspi, T.X. Liu and M. Setamou. 2001. Feeding and life history of Spodoptera exigua (Lepidoptera: Noctuidae) on different host plants. Ann. Entomol. Soc. Am., 94: 566-575. https://doi. org/10.1603/0013-8746(2001)094[0566:FAL$\mathrm{HOS}$ 2.0.CO;2

Gregoriou, C., S. Gregoriou and N. Onoufriou. 1997. Review of cultural practices, seed production, and evaluation of varieties and clones of potatoes for the period 1965-1994. Agricultural Research Institute, Ministry of Agriculture, Natural Resources, and the Environment, Nicosia. pp. 24.

Gupta, G.P., S. Rani, A. Birah and M. Raghuraman. 2005. Improved artificial diet for mass rearing of the tobacco caterpillar, Spodoptera litura (Lepidoptera: Noctuidae). Int. J. Trop. Insect Sci., 25: 55-58. https://doi.org/10.1079/ IJT200551

Hassan, S.I., M. Iqbal, M. Iqbal, A. Iqbal, M. Hussain and M. Shahbaz. 2015. Evaluation of potato "Solanum tuberosum L." accessions over wide range of environments. J. Agric. Res., 53: 93101.

Howlader, O. and M.A. Hoque. 2018. Growth analysis and yield performance of four potato (Solanum tuberosum L.) Varieties. Bangladesh J. Agric. Res., 43: 267-280. https://doi. org/10.3329/bjar.v43i2.37330

Khan, S., I. Ullah and S. Ali and Murtaza. 2020. Profitability and determinants of potato growers in district Swat of Khyber Pakhtunkhwa, Pakistan. Sarhad J. Agric., 36: 748-753. https://doi. org/10.17582/journal.sja/2020/36.3.748.753

Kroschel, J., N. Mujica,J. Okonya and A. Alyokhin. 2020. Insect pests affecting potatoes in tropical, subtropical, and temperate regions. In: The Potato Crop, Springer, Cham. pp. 251-306. https:// doi.org/10.1007/978-3-030-28683-5_8

Majeed, A. and Z. Muhammad. 2018. Potato production in Pakistan: challenges and prospective management strategies. A review. Pak. J. Bot., 50: 2077-2084.

Nathan, S.S., P.G. Chung and K. Murugan. 2005. Effect of biopesticides applied separately or together on nutritional indices of the rice leaffolder Cnaphalocrocis medinalis. Phytoparasitica, 33: 187. https://doi.org/10.1007/BF03029978

Reese, J.C., 1978. Chronic effects of plant allelochemics on insect nutritional physiology. Entomol. Exp. Appl., 24: 625-631. https://doi. org/10.1111/j.1570-7458.1978.tb02826.x

Selvanarayanan, V., M. Saravanaraman, N. Muthukumaran and J. Chacko. 2020. Harnessing host plant resistance for major crop pests: de-coding in-built systems. In: Innovative Pest Management Approaches for the $21^{\text {st }}$ Century. Springer, Singapore. pp. 119-135. https://doi. org/10.1007/978-981-15-0794-6_7

Ullah, M.I., M. Arshad, M. Afzal, S. Khalid, M. Saleem,I. Mustafa, Y.Iftikhar,J. Molina-Ochoa and J.E. Foster. 2016. Incidence of Spodoptera litura (Lepidoptera: Noctuidae) and its feeding potential on various citrus (Sapindales: Rutaceae) cultivars in the Sargodha Region of $\mathrm{Pa}-$ kistan. Fla. Entomol., 99: 192-195. https://doi. org/10.1653/024.099.0206

Waldbauer, G.P., 1968. The consumption and utilization of food by insects. Adv. Insect Physiol., 5: 229-288. https://doi.org/10.1016/S00652806(08)60230-1

Weber, D., 2013. Biological control of potato insect pests, In: Insect pests of potato: Global perspectives on biology and management, $P$. Giordanengo, C. Vincent and A. Alyokbin. Academic Press, Oxford, UK, pp. 399-437. https://doi. org/10.1016/B978-0-12-386895-4.00014-4 